Communications and Engagement at West Vancouver Memorial Library Successfully Promoting the Imagine IT Technology Fair

\section{David Carson}

David Carson is Divisional Manager, Communications, Vancouver Island Regional Library. He began working in libraries in January 2014 after working in corporate communications for various $B C$ municipalities. Since arriving at the library, David has carried on with the organization's commitment to excellence, and has been part of numerous successful and high profile communications campaigns. Although not cut from the library cloth, he has developed a deep passion for library services and helping his library thrive in today's dynamic environment.

Correspondence concerning this column should be directed to Nicole Eva and Erin Shea, email: nicole .eva@uleth.ca and eshea@fergusonlibrary.org.
A recent winner from the ALA's PR Xchange competition lets us in on some of their secrets as they describe their process for creating and promoting their first IT Technology Fair. Perhaps it will stimulate similar ideas in your library.-Editors

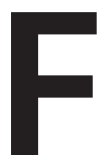

or four years running, West Vancouver Memorial Library has come away a winner at the annual American Library Association PR Xchange competition, picking up a total of nine awards in seven categories that include all formats: print, online, and video. We're a single-site library serving a population of 45,000 with a communications department of two and a small printing budget. Yet, time after time, we produce materials that resonate in our community and beyond. How do we do it? Here's an example of how we recently planned and executed the promotion for our first technology fair: Imagine IT.

On April 29 and 30, 2016, more than seven hundred people came into our library over the fair's two days: regular patrons, first-time visitors, newcomers to the community and country, families, couples, siblings, friends, and politicians. Curious grandparents were led, hand-in-hand, by their grandchildren to experience virtual reality for the first time. Entire families lined up to have their picture taken in front of our green screen and then choose from a selection of whimsical backgrounds for their photo. 3D printers hummed nonstop, producing a wide array of objects, from whistles to visitors' scanned heads to model airplanes. On every floor and in every room, library staff and community partners introduced people to digitization technology, translation software, robotics, drones, virtual reality, the library of things (lending nontraditional library items, such as tools and instruments), technology for seniors, coding, and much, much more. The predominant response was for us to do it again. As soon as possible.

How did we create a successful fair that drew crowds beyond our regular patron base? How were we able to put it all together in just a couple of months? We accomplished this with a thorough communications and engagement plan with the following key elements:

- A strong brand

- In person engagement with key people in the library and the community

- Disseminating marketing efforts out into the community

- Community participation activities leading up to the fair 


\section{AMPLIFY YOUR IMPACT}

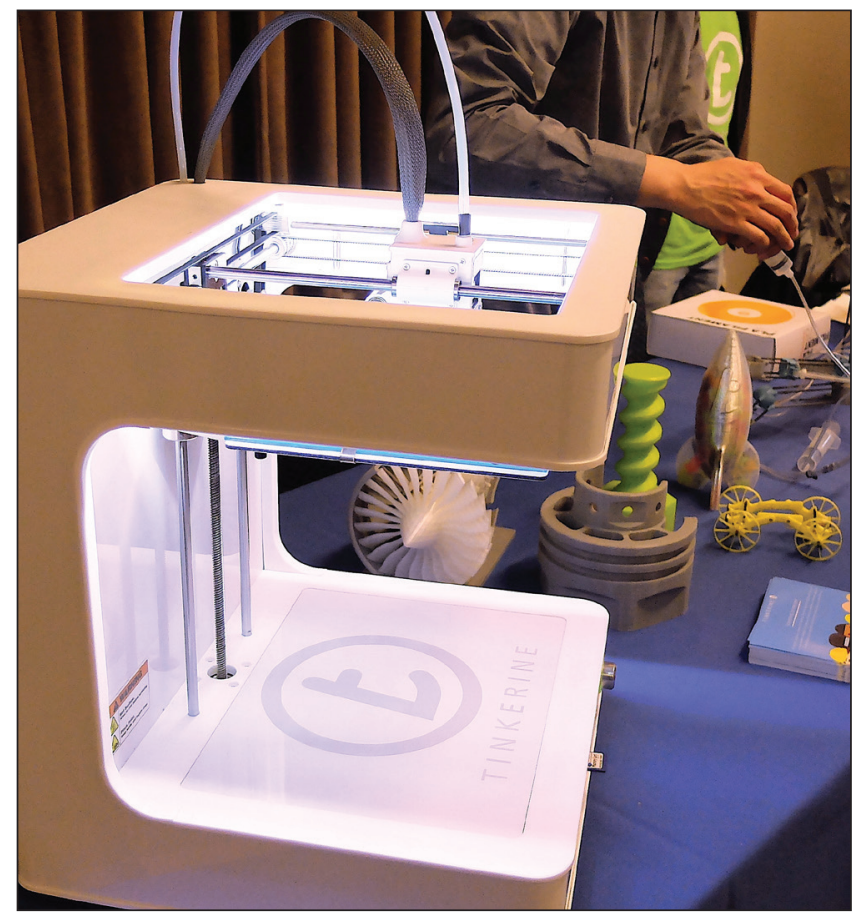

Figure 1.3D printing was one of the most popular new technologies at the fair

\section{A STRONG BRAND}

The technology fair was the key event in a community technology consultation plan undertaken to understand community technology needs and to identify responsive services, programs, spaces, and tools that would be embraced by the community and potential funders. Three groups were formed to work on this project: a key stakeholder working group, a staff advisory team, and a project team. Early on, each group was asked to brainstorm on a series of key questions:

- What is the most important thing to get out of the community consultation process?

- Who should we talk to?

- What do we think the technologies are that people want?

And, perhaps most importantly:

- What should we call our fair?

One group riffed on IT, and another on words like innovate, imagineering, reimagine, and see. Our library's deputy director and project lead, Deb Hutchison Koep, and communications coordinator, David Carson (the author of this article) took all the input away and worked closely to come to a name that would resonate across age groups, demographics, and levels of technology interest. They decided on Imagine IT: Conversations about Technology and Your

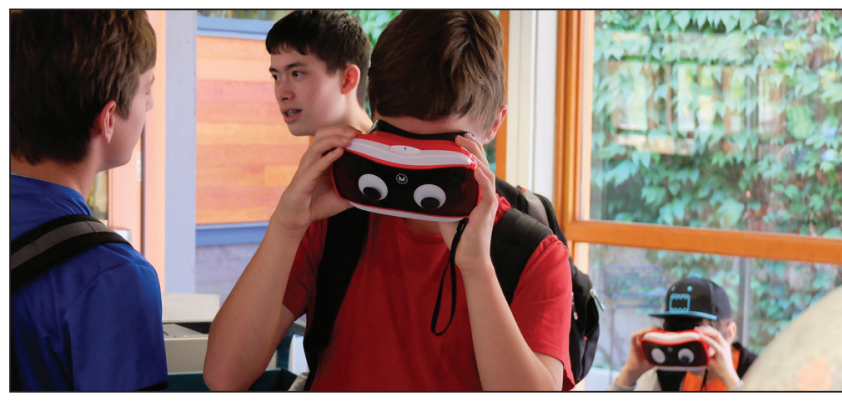

Figure 2. A teenager tests inexpensive virtual reality goggles that anyone with a smartphone can use

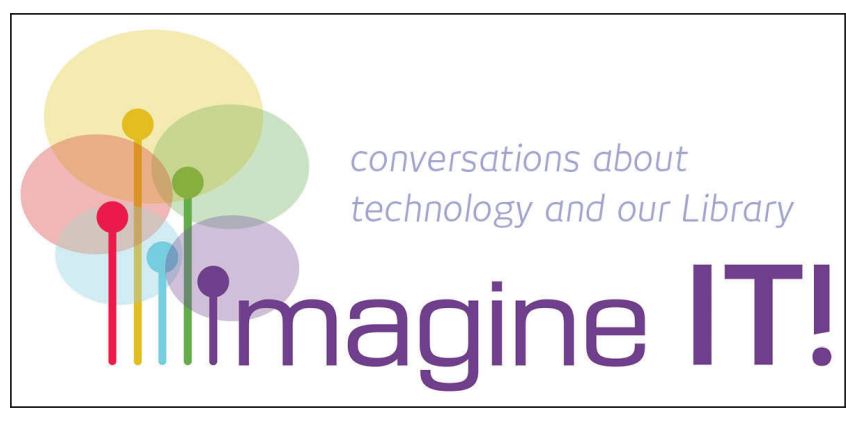

Figure 3. The logo and tagline that we crafted and designed in-house for the fair

Library, which evoked creativity, possibilities, and consultation, clearly framed within the lens of technology.

From there, Gabriele Raasch, the library's graphic designer, set to work creating a logo that evoked the intertwined nature of our role as both a community hub and a hotbed for new and emerging technology-beacons broadcasting multicoloured, overlapping signals represented this dual role quite clearly, and the use of different colours highlighted the diversity in our community and the various technologies available today.

\section{IN-PERSON ENGAGEMENT}

The second key element of our plan was in-person engagement. While we planned to push our marketing efforts into the community, we also knew that we would need to engage people in-person to get them to participate in the consultation and the fair. We set up interviews and focus groups, connecting with sixty-five people. The consultation included the following:

\section{Staff}

Focus groups were held with library managers and staff to elicit their knowledge about our community as well as planned initiatives and possibilities. We asked staff to share their observations about the community's attitudes, 
frustrations, needs, and desires when it came to technology, as well as their thoughts about what technologies could potentially disrupt or transform library services.

\section{Key Stakeholders}

Members of the library board and library foundation board were invited to focus groups to share their perspectives as both stakeholders and community members. As with our staff focus groups, participants were asked to describe their perceptions of community needs, then to share their thoughts about the role and value of the library with respect to technology.

\section{District of West Vancouver}

To expand our knowledge of community technology needs and priorities beyond the library sphere, we interviewed West Vancouver staff from key departments:

- Communications and Community Relations

- Community Services (Community Centres, Seniors Activity Centre, Youth Services)

- Economic Development

- IT Services

\section{Community Organizations and Businesses}

We interviewed representatives of selected business and community groups to ask about their clients' needs and priorities, their perceptions of the community's values and aspirations, and their thoughts about how the library might better support their clients or their organization. Groups to contact were identified and prioritized by the key stakeholders working group and the staff advisory team. We interviewed staff from the following organizations:

- Capilano University

- First Nations Technology Council

- GLUU Technology Society (a local nonprofit teaching technology to seniors)

- Kay Meek Centre

- North Shore Employment Services Centre (WorkBC)

- North Shore Multicultural Society

- Silver Harbour Seniors Centre

- Vancouver Maker Faire Society

- West Vancouver Community Foundation

- West Vancouver Chamber of Commerce

- West Vancouver Schools

- West Vancouver Seniors Activity Centre (advisory board members and volunteers)

- Zen Launchpad (a North Shore makerspace and incubator)

To supplement our conversation with the North Shore Multicultural Society about the specific needs and aspirations of newcomers, we also held two focus groups with
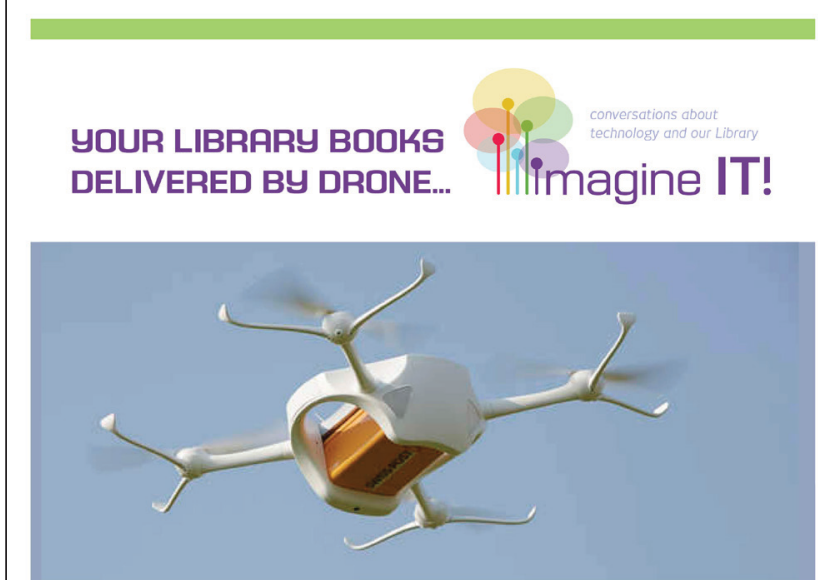

Touch, test and tinker at our TECHNOLOGY FAIR

Try a 3D printer. Digitize an old photo or slide. Learn to code. See robots in action. And more... Friday, April 29, 4 - 8 p.m. (cash bar) Saburday, April 30, 10 a.m. - 4 p.m. wvml.ca/imagineit

Gest vancouver 1950 Marine Dive, West Vancouver | 604.925.7403 westvanlibrary.ce

Figure 4. An example of the posters placed throughout the library and community with audacious statements to grab people's attention and get them thinking about what technology can do for them

newcomers from our Library Champions program (a partnership with the provincial government that brings newcomers together and uses local libraries as vital hubs in which to connect and grow).

Together, these conversations created a picture of the community's current aspirations and preoccupations, both generally and with respect to technology. Many of these groups expressed keen interest in our technology fair and were helpful in spreading the word through their networks. They are all to be thanked both for taking time to speak with us and for increasing awareness about the fair.

\section{DISSEMINATING MARKETING EFFORTS INTO THE COMMUNITY}

Since we wanted to cast a wide net and bring new people into the library at the fair, we went well beyond our typical marketing efforts of homepage features, online and print calendars of events, posters in the library, social media updates, and word-of-mouth.

In addition to all these approaches, we expanded our scope by doing the follow: 
- Placing ads in both our local English newspaper and our community's most widely read Persian publication

- Reaching out to the local paper with a pre-fair photo-op

- Sending out a one-time e-blast to our e-newsletter subscribers with a link to the programs planned for the fair

- Creating posters with audacious statements and placing them throughout the community

- Sending an email invitation to a large and targeted list of key stakeholders, including the mayor, city council, and members of our provincial and federal government

- Printing eye-catching promotional postcards and placing them at every service point in the library

- Paying for boosted posts on our Facebook page

- Sending scheduled promotional Tweets

- Reaching out to community and municipal partners, including the community centre, chamber of commerce and others who retweeted and shared our posts

In addition, in mid-April, we launched a series of webpages created by the staff who were also creating the booths at the Imagine IT technology fair. Many of these webpages had interactive elements and all were promoted heavily through our social media campaign as well as our e-blast and email to key stakeholders. The webpages featured these elements:

- 3D Printing-Creating in a New Dimension

- Coding-Computational Thinking in the Digital Age

- Translation on Demand-Communicating with the World

- Digital Services that Come to You-The Library at Your Side

- Virtual Reality and Augmented Reality

- Tech Skills Development-Learning 101

- Digitization-Preserving the Past

- Library of Things-Why Own when you can Borrow?

- Video and Audio-Dream, Create, Record

- The Interconnected World-How Big Data is Shaping our Lives

Last but not least, we drafted key messages for our library staff and posted them to our intranet so that library staff could clearly, articulately, and consistently communicate to patrons what we hoped to accomplish through the consultation and fair. Messaging was as follows:

- We want to hear from you about the technologies we should bring on board over the next few years.

- We're trying to get people thinking about technology in
Table 1. Marketing Tactics and Timeline

\section{Tactic}

Produce posters for fair, hang in

library/community

Inform North Shore News about Tuesday, April 5

fair, solicit promo

Website banners to promote fair Starting week of April 5

Update events calendar Week of April 4

Post first graffiti wall (digital and Monday, April 4

in library)

Weekly Facebook posts—Graffiti Tuesday, April 5-May $1+$

Wall Questions

Facebook ad campaign

(promoted posts) fair promo

partners

Social media posts for fair

Starting Tuesday, April 5, weekly until fair

Tuesday, April 5-April 29 (May

6 for digital)_leverage partner

social media channels

Post second graffiti wall (digital Monday, April 11 and in library)

Create and deliver invites/ Week of April 11

postcards for fair

E-vite to fair (sent to key Week of April 11 members)

Post digital tech fair webpages Monday, April 18-Friday, May 6

Post third graffiti wall (digital and Monday, April 18

in library)

E-blast (one time to e-newsletter Monday, April 18

sign-ups)

Run ad in North Shore News Wednesday, April 20

(print)

Run ad in Paivand-Persian Friday, April 22

paper (print)

Post fourth graffiti wall (digital Monday, April 25

and in library)

Technology Fair

April 29 and 30

Surveys (onsite, offsite and Sunday, May 1-Saturday, May 7 digital)

new ways and considering how it can power their interests, passions, learning and careers.

- The consultation will include in-person and digital outreach - we want to give people as many opportunities as we can to have their voice included.

- All ideas are welcome, big and small. Even if it seems audacious or trivial, we want to hear about it.

- We're staying true to what the library means to many of you. That means books, friendly faces, and cozy spaces to curl up and read. The changes we're making are in addition to the core services that we have always provided.

The complete list of tactics and timeline is in table 1. 
Table 2. Program Success Factors

\section{Success Factor}

A good turnout of regular users with some new visitors and reflecting some diversity (age, gender, language, etc.)

Engagement with influential members of our community
How measured?

\# attending staff observation

Reported by hosts and staff
Goal?

150 attending over 2 days Visitors include younger (kids, teens) and older (seniors) folks, as well as some newcomers

10 "VIPs"
\# passports completed

\# exit surveys completed

\# interactions at each booth staff observation
$>60 \%$ of passports completed

$>20 \%$ complete exit survey

$>30$ interactions/responses at each booth Staff report "buzz," engagement, ideas

\section{Result?}

$533+$ attended over 2 days

Staff, hosts, guests reported broad diversity in attendees

13 identified "VIPs"

- 6 Lib board members including 3 hosts

- 3 Fdn board members including 1 host

- 2 politicians (1 MLA, 1 councillor)

- 2 District managers

$40 \%$ of passports completed

$34 \%$ completed exit survey

All but 1 feedback board had $>30$

responses (up to 260)

Staff reported moderate to high degree of interest in all topics and captured stories and ideas

\section{COMMUNITY PARTICIPATION ACTIVITIES}

Since the main objective of the project was to understand our community's technology needs, we wanted to create mechanisms by which the public would give us feedback on their wants, aspirations, and challenges. To do so, we implemented two tools: graffiti walls and surveys.

Each graffiti wall posed a probing question and gave the public free rein to write anything that came to mind. They were branded with the Imagine IT logo and colors, which tied them to the upcoming technology fair. Starting on March 25 and running for four weeks, we posted the following weekly questions on large easels in various locations in the library, on our website, and through our social media channels:

- What technology would you like to use/learn about at the library?

- How is technology changing our community?

- What technology should the library invent?

- How does technology help or inspire you?

We collected 412 total pieces of feedback over the month. We saw that most respondents entered into the spirit of the exercise. A few had some fun pushing the envelope-robot librarians, for example - and there was a consistent presence of expressions of discomfort with technology. The vast majority of feedback was positive and constructive. The online graffiti walls generated some lively discussions and we were pleased to see so many express their views on technology and the potential role the library could play.

To complete our public consultation, we ran surveys to round out our understanding and to reach a broader audience, including offsite users. In addition to mining the results of an online survey that we had already carried out in 2015, we ran two additional surveys: one through our website and one offsite or "intercept" survey.

The website technology survey ran for ten days in early May 2016, receiving 142 responses. In addition, one of our board members translated the survey into Chinese and distributed it through her network. This survey was answered by a further 25 people.

To gather feedback from our secondary school population, we created a modified version of the survey and distributed it through our school-district contacts. We received 150 West Vancouver student responses to this survey.

To be sure that we were capturing public feedback from nonlibrary users, two-person teams conducted surveys out in the community over four half-days. Locations included Park Royal Shopping Centre, the Ambleside and Dundarave neighbourhoods, the Seawalk, Caulfeild Village, and the neighbourhoods of Gleneagles and Horseshoe Bay.

\section{GAUGING SUCCESS}

After all the planning, meetings, marketing, and coordinating, the day of the fair arrived and we were filled with anticipation, excitement, and energy. We feared we might be too successful ... or maybe not successful enough for all the effort that we had put in.

We had predetermined success factors and as the fair rolled out, we kept tallies of them (see table 2).

The passports, we thought, would be an excellent way for us to assess engagement. Each person who walked in the door received a passport that they could bring to each booth to earn a sticker. Once all of the stickers were collected, they were supposed to enter their passport into a draw to win prizes by dropping it off on their way out. While we printed 650 passports and gave out 533 to people attending the 


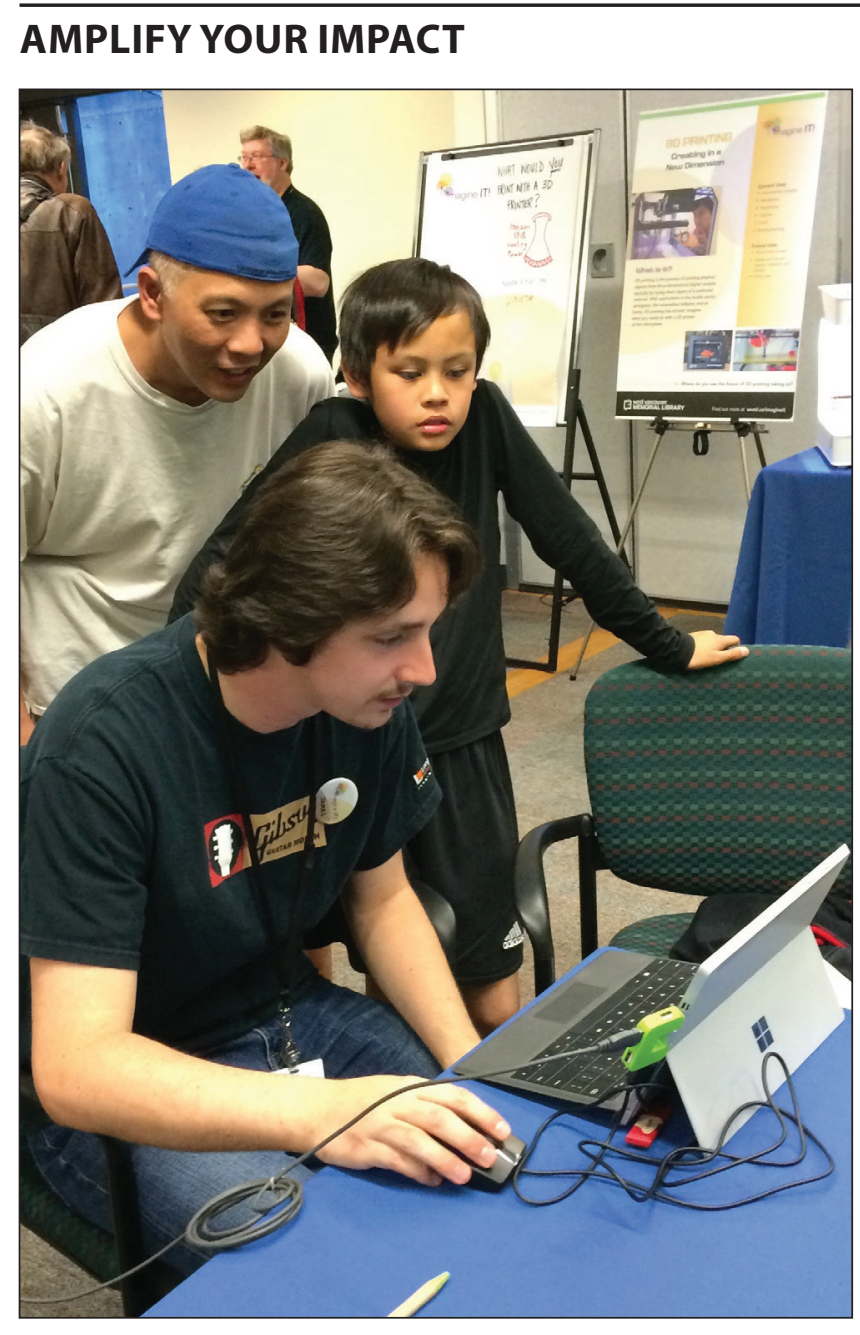

Figure 5. A library staff member works with a father and son at our inaugural Imagine IT technology fair

fair, far fewer were returned to us. Often families chose to get stickers only for their children, or for one member of a couple, and many chose to hang on to their passports rather than turning them in.

We also ran an exit survey that was completed by 183 people, and a ranking exercise where participants were given seven index cards, each containing a potential role for the library, and were asked to sort them into priority order:

- Community technology projects (examples: mapping community data; hackathons)

- Delivering library services digitally (examples: improved e-book access; personalized reading recommendations; delivery by drone)
- Digitization and digital conversion (examples: scanning slides, photos, and documents; converting home videos to digital formats)

- Introducing new technology (examples: emerging tech talks, lectures; technology fairs; recommended apps)

- Spaces and equipment for innovation and collaboration (examples: maker spaces; 3D printing)

- Technology skills development (examples: computer literacy programs; coding classes; online learning)

- Video and audio production and editing (examples: recording oral histories; creating short videos)

Over the two days of the fair, 133 people participated in this activity. By weighted score, the rankings were

1. Introducing new technology;

2. Technology skills development;

3. Delivering library service digitally;

4. Spaces and equipment for innovation and collaboration;

5. Digitization and digital conversion;

6. Community technology projects; and

7. Video and audio production and editing.

Finally, everyone who worked the booths-library staff, teen volunteers, and members of our board and foundation-were asked to complete surveys at the end of each day to describe levels of interest in their booth, the aspects or applications of the technology that seemed to inspire the most "buzz," the apparent demographics of those visiting their booth, and any other stories or feedback. The results were always positive, with each booth posting high numbers, indicating strong degrees of interest and engagement from those who attended.

The Imagine IT technology fair was a success on almost every level. We had strong numbers, great diversity, high interest, and an overwhelming consensus that it should become an annual event. Our library, we learned, is seen in our community as a place where people should expect to find new and emerging technology - that we can be leaders in this regard. Our multiplatform campaign ensured that we reached well beyond our physical walls to penetrate deeply into our community, and we now have a blueprint for how to market a new fair to an even larger audience in the years ahead. 